\title{
Digital media and the challenges for media education
}

\author{
Armanda Pinto da Mota/Matos, Maria Isabe Festas, Ana Maria Seixas \\ Faculty of Psychology and Educational Sciences \\ University of Coimbra, Portugal \\ corresponding e-mail: armanda@fpce.uc.pt \\ postal address: Faculdade de Psicologia e de Ciências da Educação da Universidade de Coimbra, \\ Rua do Colégio Novo, 3000-115 Coimbra, Portugal
}

\begin{abstract}
The ongoing evolution of digital media and the possibilities of communication and access to information which they offer draw particular attention to the need to develop citizens' effective, responsible and critical behavior not only as consumers, but also as communicators and media message producers. This article presents an analysis of the challenges that digital media poses to the education of young people, highlights the importance of a wide reflection on the concept and aims of media literacy, and offers suggestions regarding possible lines of action.
\end{abstract}

Keywords: Digital media, media education, young people, digital citizenship

Citation: Matos A.P., Festas M.I., Seixas A.M., 2016 "Digital media and the challenges for media education", Applied Technologies and Innovations, Vol.12(2), pp.43-53, http://dx.doi.org/10.15208/ati.2016.04

\section{Introduction}

The current communication context is characterized by the ubiquity of the media, which, together with digital technologies, mediate a large part of our daily activities and interactions in family, school, work, leisure, and other personal and social contexts. The numerous opportunities offered by digital media, in terms of access to information, but also related to the creation of new spaces and communication tools, pose new and great challenges to the education of young people, particularly in what concerns to media education, understood as a process aimed at improving citizens' media literacy (JacquinotDelaunay, Carlsson, Tayie, Pérez Tornero, 2008).

The ongoing evolution of digital media, which translates into a convergence of different media in single platforms, and the widespread use of mobile devices, is accompanied by children and young people with the naturalness of who was born and grew up with computers and the Internet. This familiarity and ease of use of young people, labeled digital natives (Prensky, 2001), has often been linked to a higher level of media literacy skills. However, such an association has an underlying concept of literacy that

This work is supported by the $\mathrm{R}+\mathrm{D}+\mathrm{I}$ Project entitled "Media competences of citizens in emerging digital media (smartphones and tablets): Innovative practices and educational strategies in multiple contexts", EDU2015-64015-C3-1-R (MINECO / FEDER), financed by the European Regional Development Fund (ERDF) and Ministry of Economy and Competitiveness of Spain. 
overestimates an instrumental dimension, based on functional or operational skills (Buckingham, 2008), which deserves to be analyzed and object of critical inquiry, since it attributes to technologies a neutrality that they do not have, and also ignores the ideological dimension involved in their action. In the last decades, this perspective has been reflected in a growing emphasis on the importance of introducing Information and Communication Technologies (ICT) in the most varied educational contexts, particularly in the formal educational context (visible also in Portugal ${ }^{1}$ ). Despite the effort to equip schools and integrate digital media as a resource in education, the initiatives developed have not been accompanied by an equal investment (political, economic and educational) in creating spaces and times necessary for the integration of the media as an object of study and reflection. However, the evolution of digital technologies, and the possibilities of access to information, communication and production that they offer demand particular attention to the need to develop in the young people skills for an informed, critical, secure and socially responsible digital media use.

This article presents an analysis of the challenges that digital media poses to the education of young people, highlights the importance of a wide reflection on the concept and aims of media literacy, and offers suggestions regarding possible lines of action.

\section{The new challenges of digital media}

The reflection we propose focus on the changes that new media had brought to communication and social relationships, as well as on the role of young people as consumers, and simultaneously communicators/producers of media messages and texts. In fact, digital media have brought countless opportunities and benefits in different areas, namely in terms of the amount and diversity of information offered, as well as regarding communication. In terms of information, the dimension and diversity offered by new media are only comparable to the wide multiplicity of the challenges involved in the information-seeking process itself, in the analysis, selection, and evaluation of the information found, and in the appropriation, integration and organization of information in a useful knowledge structure. Media education becomes fundamental to the development of skills needed to accomplish these tasks, and to lead people to operate in higher levels in the continuum of media literacy, as referred by Potter (2000, p.5).

People operating with a high level of media literacy have a strong, broad perspective. They actively use a set of highly developed skills to place a media message inside the context of a well-elaborated knowledge structure and so are able to interpret any message along many different dimensions. Thus, media literate people have greater control over media messages.

Beyond the process of analyzing, selecting, evaluating and even taking a social or moral position in relation to the information/media messages found, the wide ocean of information offered by new media posits another challenge related to the informationseeking process itself. To search for information in an effective way, that serves the purposes for which it is performed, it is necessary do develop skills to search and find information in complex contexts that are constantly changing, which leads Callister to state that ICT dilute the line separating the information-seeking process from the process of meaning construction from that information: "In cyberspace, the journey cannot be separated from the destination (Callister, 2000, p.407).

${ }^{1}$ The Portuguese Technological Plan for Education constitutes an example (see http://www.dgeec.mec.pt /np4/100/) 
In addition to the changes related to information, digital media had brought significant alterations to communication and social relationships, which are the particular focus of our reflection in this article.

With the ongoing evolution of ICT, citizens are no longer simple consumers, and have increasingly become communicators and producers of media messages and texts. New media offer interactivity, instant communication, new spaces and forms of social interaction (e.g., emails, online games, social networking sites), and tools for media production and sharing (e.g., video sharing websites, blogs). These new features of media have led to an expansion of media literacy, to include the new dimension of production, as referred by Ohler (2010).

With regard to young people, communication and social interaction are nowadays mediated, to a large extent, by digital media, in particular by social networking sites such as Facebook, Myspace or Instagram. As communication moves to cyberspace, questions regarding communication and social skills, social and ethical norms of conduct need to be addressed in these new contexts of social interaction. Also the communication problems, misunderstandings, potential conflicts, rupture of relations which can occur in young people relationships are transferred to online communication, take on new features and have the potential to manifest themselves in broader contexts and with long lasting impact.

The opportunities for communication and creation represent a qualitative leap ahead from the mass communication model (Pérez Tornero, 2008), demanding a deep reflection on the literacy skills which are required to be effective communicators and active citizens.

This reflection should be based on knowledge and understanding of the particularities of online communication and their impact on young people's behavior.

\section{Communicating behind the screen}

The interaction between young people takes place in different spaces and contexts. In the eyes of adults, some of those spaces are considered "real", others "virtual", while for young people they simply constitute different contexts of a continuum where their social relations develop and consolidate. Despite the increasing tenuous line separating these different communication contexts, online communication presents specificities that must be considered, analyzed and understood in order to allow the development of effective communicators. It is fundamental that young people learn to recognize these characteristics, which largely reconfigure the social contexts in which they live.

Danah Boyd identify four properties of mediating technologies which decisively separate unmediated publics from what she calls "networked publics" (Boyd, 2007, p.9). Those properties are persistence, searchability, replicability and invisible audiences. Persistence refers to the record of what is published online and that remains registered over time. Searchability means that information recorded can, in turn, be searched and found, using the numerous tools provided by technologies. Digital footprints thus put into question the feeling of invisibility provided by the screen. Replicability refers to the fact that what is published can always be copied, replicated, modified, leading to losing the notion of where or to whom the information arrived and, often, of who is the author of the information. Finally, and in conjunction with the three above-mentioned properties, the invisible audiences mean that we cannot control and know who is "reading" what we write or post, which becomes easily and rapidly accessible to an immensely broad audience. 
These properties of mediating technologies have deep implications in the reconfiguration of the spaces of social interaction of today's young people, and so, their knowledge about those characteristics and their implications in their present communicative acts, as well as in their future, deserve to be the subject of reflection and debate.

In addition to these properties, other characteristics of technology-mediated communication should be discussed, especially in view of their potential impact on human behavior.

One of the characteristics of online communication refers to the (illusion) of anonymity or invisibility created by new media (Amichai-Hamburger, 2007; McKenna, 2007; Willard, 2007, McKenna, 2015). Behind the screen, people may feel protected from identification and from the potential consequences that similar actions would have in real life. Additionally, anonymity and invisibility make the consequences of online behavior more difficult to predict. Online communication may thus produce a disinhibition effect, and lead young people to act in ways that they would be less likely to act in face-to-face interaction.

Moreover, invisibility enabled by the internet allows young people to explore different aspects of their identity and to take on virtual identities. The possibility to explore different aspects of identity can play an important role in adolescent development, and have positive effects in terms of self-disclosure, or contrariwise, contribute to performance of socially undesirable behaviors, such as behavior which is harmful to others (Valkenburg and Peter, 2009, 2011; Willard, 2007; Amado and Matos, 2015)

Another particularity of communication in cyberspace consists in a reduction of social and contextual cues and tangible feedback, as referred by Willard (2007). Aspects as important as the tone of voice, the facial expression, gestures, posture and other components of body language play a central role in face-to-face interaction, by helping to understand the impact of our acts in our interlocutor and to make continuous adjustments during interaction. However, in cyberspace, those social and contextual cues are significantly reduced, what makes it difficult to understand the impact that our action can have on the person that is in the other side of the screen, and consequently, reduces the opportunities for empathy. The ability to understand the perspective of another person has been negatively associated in several studies to harmful and aggressive behaviors (e.g., Gini, Albiero, Benelli, Altoè, 2007; Almeida, Correia, Marinho, Garcia, 2012), which show the impact that the difficulty to feel empathy may have on young people's decisions about how to behave behind the screen.

Online communication also has the potential to enable two types of communicative acts that may seem contradictory, but constitute, in fact, the "two sides of the same coin". Online communication is characterized by instantaneity, resulting from an ongoing ICT evolution that creates new communication tools and adds constantly new features to Internet communication applications (e.g., video calls, instant messaging, social networking sites). This instantaneity can encourage impulsive or thoughtless behaviors, and it is the reason why many internet safety campaigns used slogans such as "think before you click" or "think before you post". On the other side, online communication simultaneously offers the possibility of greater control of the communication, which may seem contradictory. Technology allows to choose the moment in which a person sends a message, to review the message before sending it and to shape more effectively what it means, and, thus, to communicate more strategically (McKenna, 2007). This constitutes an opportunity to train communication and social skills, increases the probabilities of being successful and positive reinforced, which can end up having positive effects in terms of self-esteem and self-efficacy. 
Therefore, we can conclude that the characteristics mentioned above are not positive or negative by themselves. The disinhibition effect promoted by Internet, as Willard (2007) highlights, may lead to positive or negative consequences. It can help young people in the process of identity development, allowing to explore multiple dimensions of their personality, it can contribute to disinhibit people who have poorer social skills or feel more socially inhibited, and promote self-expression, among many other benefits. Nevertheless, the same above mentioned characteristics may facilitate harmful behaviors, and the contact to harmful contents (Willard, 2007; Valkenburg and Peter, 2009; 2011). As referred in the UNESCO Kit for Teachers, Students, Parents and Professionals about media education: "Digital media-and particularly the internet- significantly increase the potential for active participation; but they also create an environment of bewildering choices, not all of which can be seen as harmless" (Frau-Meigs, 2006, p.22).

This ambivalence strengthen the need to reflect and discuss the challenges which are faced by media education, in order to help young people as participants in communication mediated by technology, and as producers of media messages and texts.

\section{Media education and digital media}

Although digital media add new features to communication and raises new questions, the conceptual framework developed during last decades in the field of media education is still considered a useful and comprehensive approach to address digital texts and to guide the work of media educators (see Buckingham, 2008). According to one of the Core Principles of Media Literacy in the United States, media literacy education expands the concept of literacy (i.e., reading and writing) to include all forms of media (Scheibe and Rogow, 2012, p.36). Based on this core principle, we can state that media education should promote the development of critical analysis and evaluation skills, that is, the development of habits of enquiry (learning to ask questions), as well as skills of expression (Buckingham, 2008; Scheibe and Rogow, 2012).

The European Commission, which has been playing an extremely relevant role in terms of boosting media literacy through several initiatives, directives and recommendations (e.g., Directive 2007/65/EC of the European Parliament and of the Council of 11 December 20071; Council Conclusions of 27 November 2009 on Media Literacy in the Digital Environment, 2009/C 301/092), defines media literacy "as the ability to access the media, and to understand and critically evaluate different aspects of the media and media content. Media literacy also includes the ability to communicate in a variety of contexts" (Commission Recommendation 2009/625/EC of 20 August 20093).

Within this perspective, several proposes of key-questions / key-concepts have been presented by several institutions and authors, to guide the work in the field of media education, such as Bazalgette (1989), Férres and Piscitelli (2000), the Ontario Association for Media literacy (Duncan, Pungente and Andersen, 2002), Buckingham (2003) and the United States National Association for Media Literacy Education (Scheibe and Rogow, 2012). The set of the four broad key concepts (representation, language, production and audience) proposed by Buckingham (2003), and used in the UNESCO Guide for Teachers, Students, Parents and Professionals (Frau-Meigs, 2006) are, in the author perspective, an useful framework to study digital texts and help to formulate useful

\footnotetext{
${ }^{1}$ http:/ / eur-lex.europa.eu/LexUriServ/LexUriServ.do?uri=OJ:L:2007:332:0027:0045:EN:PDF

2 http:/ / eur-lex.europa.eu/LexUriServ/LexUriServ.do?uri=OJ:L:2007:332:0027:0045:EN:PDF

${ }^{3}$ http://eur-lex.europa.eu/legal-content/EN/TXT/?uri=uriserv\%3Aam0004
} 
questions about digital media (Buckingham, 2008). Regarding representation, users need to understand that media represent the world and evaluate critically media representations, skills which also apply to the representations offered by digital media. A second broad concept is language. Users need to use the language of different media, but also understand the rhetoric and the grammar of those media. The concept of production may be very useful if adapted to study who, in digital media, "is communicating to whom and why" (Buckingham, 2008, p. 79). Finally, but not less important, audience constitutes a key concept to make young people reflect on their own role as users and communicators, as well as the role of others in the relationship they establish with media.

Within this perspective, the aim of media education continues to be to develop the skills of questioning and critical thinking necessary for understanding the messages and the impact of the media. However, given the communication and production possibilities offered by digital media, particular attention should be paid to the development of skills of expression, that is, to develop skills necessary to write different forms of media. According to the NAMLE, "the purpose of media literacy education is to help individuals of all ages to develop the habits of inquiry and skills of expression that they need to be critical thinkers, effective communicators and active citizens in today's world"1. Digital media enables citizens to be more active and participative as communicators and the increased opportunities for participation bring with them increasing responsibilities as participants in the media culture, implying the ability to communicate in an effective, critical and socially responsible way.

This constitutes, in our perspective, an enormous challenge faced by educators in general, and especially by those who work and chose to invest in promoting young people's media literacy.

\section{Media education and digital citizenship}

Rethinking media literacy, taking into account interpersonal communication mediated by digital media, implies understanding the role media play in young people's relationships and social life. In fact, young people communication is largely mediated by digital media, for whom the boundaries between what happens offline and in media mediated contexts is rather blurred, and characterized by continuity, fluidity and mutual contamination.

In this context, it is expected that young people are able to communicate using text, image and sound, but are also able to reflect critically on their own acts of communication. These concerns should underpin the aims and methodologies of media education. As referred by Buckingham (2008, p.86), "in the context of media education, the aim is not primarily to develop technical skills, or to promote 'self-expression', but to encourage a more systematic understanding of how the media work and hence to promote more reflective ways of using them".

In line with this perspective, according to the European Charter of Media Literacy, citizens should be able to "Use media creatively to express and communicate ideas, information and opinions; Identify, and avoid or challenge, media content and services that may be unsolicited, offensive or harmful; Make effective use of media in the exercise of their democratic rights and civic responsibilities"2.

These new challenges, resulting from the potentialities offered by new media in terms of communication and production, are therefore associated with an ethical dimension.

\footnotetext{
${ }^{1}$ https://namle.net/publications/core-principles/

${ }^{2}$ http://www.euromedialiteracy.eu/charter.php?id=3
} 
Bawden (2008, p.30) refers to a central component of digital literacy, related to attitudes and perspectives, a moral dimension that should frame the use of the skills and competences involved in media use: "'Moral/social literacy' reflects the need for an understanding of sensible and correct behavior in the digital environment and may include issues of privacy and security".

Issues of privacy and security have been largely discussed during last years by general public, researchers, as well as the media themselves, as a consequence of the risks involved in the use of digital media by young people, such as sexual harassment, the contact with undesirable and harmful contents, or risks related to harmful behaviors perpetrated through digital devices, such as cyberbullying.

The discussion and the studies carried out (Kowalsky et al., 2014, Mascheroni and Cuman, 2014; Aboujaoude, Savage, Starcevic, Salame, 2015; Smith, 2015) have significantly contributed to the understanding of the nature and characteristics of those risks, and have also produced important resources intended to help young people developing a safe and critical use of media, as well as to help parents, teachers, schools and the wider community in developing the necessary skills to support and educate young people in their use of digital media ${ }^{1}$. However, it is still necessary a significant effort and investment in the area of media education, which represents, in our view, a key strategy to prevent the risks of media use by young people, if grounded on a comprehensive approach, aimed at their empowerment towards digital citizenship.

Hobbs (2010, p.viii) defines as one of the core competencies of citizenship in the digital age the ability to "Reflect on one's own conduct and communication behavior by applying social responsibility and ethical principles". Whether young people create a profile on Facebook, post a message on a friend's Facebook wall, play online games with friends, collaborate on a wiki, write a blog, comment on the news online or create and share a multimedia document, it is still fundamental that young people learn to ask the right questions about the contents which are being produced, the meanings conveyed, the language chosen to publish them, the technological contexts best suited to share them, to whom those contents should be addressed to and to whom could become useful, and the impact they can produce on those who receive them.

Some key questions are proposed by Sheibe and Rogow (2012, p.59):

- Purpose - Why am I making this?

- Response - What kind of actions do I expect people to take in response to this message? What are the likely or possible consequences?

- Interpretations - What do I learn about myself from my role in creating this message? Am I representing my best self?

- Impact-What's my responsibility to my audience? Who might benefit? Who might be harmed, and in what ways?

To reflect on own conduct as communicator and media messages producer, therefore, people imply skills of enquiry and critical thinking. These skills of enquiry and critical thinking, when promoted by media education, will contribute to young people's recognition of the need for social norms of behavior, to the development of their sense of responsibility for their actions online and offline, and to the awareness that those actions will be reflected in their relationship with others. Although those "others" today may be

1 The training manuals and guidebooks developed in the context of international projects funded by the European Commission, in which authors of this article were involved constitute examples of those resources, which are available online and can be used by different professionals (see Jäger, Stelter, Amado, Matos, \& Pessoa, 2012; Matos and Seixas, 2016). 
behind the screen, media education can raise awareness of the fact that even so they will feel the impact of their behavior and that this impact can extend to life outside the screen.

All this reflection leads us to conclude about how challenging, and extremely relevant role is played by educators in general and in particular by media educators. In an always changing communication landscape, with the increasing use of mobile devices, educators need to rethink traditional mediation strategies and adapt them to "nomadic communicators" 1 . In fact, the increasing use of mobile devices to access Internet ${ }^{2}$ places in young people's pockets numerous communication possibilities, making more difficult supervising, as well implementing more active mediation strategies, aimed at promoting evaluation and critical thinking skills. This relatively recent evolution towards the "Pocket internet" highlights the full pertinence and topicality of Masterman's perspective on media education, especially with regard to its aims: "primary objective is not simply critical awareness and understanding, it is critical authonomy" (Masterman 1985, p.25).

\section{Conclusion}

The novelty of digital media, as it happened each time a new medium of communication emerged and its use became widespread, involves the potential risk of promoting, among adults and in the school context, an approach that aims to protect children and young people of the effects and negative influence of the media, a protectionist approach, focused on the adoption of restrictive measures in terms of access and use or in initiatives that are intended to tell them what to do or not to do, use or not use. However, this approach runs the risk of widening the gap between school culture and the daily experiences of young people, which are largely mediated by digital media. In addition, this approach can transmit to young people that adults do not understand or value their experiences and preferences.

This approach has as many disadvantages as the technological approach mentioned earlier in this article, which is based on the assumption that the use of the media is positive per se, and a guarantee of social inclusion and citizen participation.

An alternative approach is nevertheless possible and desirable, if the aim is to understand that media are a part of young people's life, and to lead students "to reflect and think critically about what actions they might take to ensure that the role of media in their lives is a healthy one" (Scheibe and Rogow, 2012, p.56). This approach may be developed by media educators and educators in general by assuming a pro-active attitude regarding the use of digital media in educational contexts, especially in school, institution that have an irreplaceable role in promoting students' media literacy.

Part of that attitude involves acknowledging students' expertise regarding media. Students' knowledge and expertise in terms of functional and operational skills, if used in school collaborative activities, could be a valuable starting point to promote a culture of sharing, in the context of which they feel comfortable to talk with adults about their online experiences. In this context, opportunities are created to young people's reflection and to

\footnotetext{
${ }^{1}$ Expression used by Pérez Tornero and Varis (2010, p.38) to refer to active multimedia users.

2 According to Eurostat (2016), the $36 \%$ of individuals in 2012 aged 16 to 74 within the EU-28 who accessed internet on a portable computer or handheld device via mobile or wireless connections increased to $57 \%$ in 2015. In Portugal, $25.7 \%$ of citizens and $39.3 \%$ of Internet users access the Internet through tablets, while among the younger individuals (up to age 44) the percentage rises to more than $42 \%$ (http://www.marktest.com/wap/a/n/id 1f3c.aspx).
} 
"ask the right questions" about media culture and about their own use of media to communicate.

Activities of production are also likely to promote the reflection of young people on the intentions and meanings conveyed by the media. Digital media offer enormous possibilities for the design and development of production activities in an educational context. However, it is necessary for these activities to be accompanied by an incentive to analyze and critically reflect on the decisions that are made throughout the production activities and it is at this level that educators have a privileged function because, as emphasizes Ohler (2010, p.213), "this kind of reflection does not come naturally in the flurry of media creation".

Another strand that is worth exploring in media education consists in involving students in initiatives aimed at raising peers awareness of the characteristics of digital media and their implications in terms of online practices and etiquette. Several studies have shown that students benefit from education aiming at empowered them to communicate online with others according to ethical principles and netiquette, but also about e-safety (Snakenborg, Van Acker, Gable, 2011; Cassidy et al., 2013). Given the increasing importance of peers as children grow up, to work together with students in raising awareness initiatives and even giving them a leadership role in creating a school culture that favors a positive use of digital media can bring great benefits.

In addition to the aforementioned possibilities of action, media education presents a characteristic that, in our view, contains countless potentialities for the formation of critical thinkers and active citizens in the construction of participatory citizenship: media education is inseparable from education for values. This means that when media educators analyze with students TV advertising or persuasive communication on digital media, they promote the ability of students to recognize the values underlying the ads being analyzed and to take a moral position in relation to them.

When media educators choose to reflect on curricular contents, based on a news published in the newspaper of the day, they create opportunities to raise questions about who wrote the news, with what intentions, and what values underlie the political or social decision making regarding the subjects addressed.

When media educators decide to address Internet security issues based on a video that portrays a case of cyberbullying, they create opportunities for reflection on the values of friendship, solidarity, while simultaneously promote empathy.

When media educators engage with students in creative activities on a particular social theme, the research tasks required to develop those activities promote the confrontation with the multiplicity of representations that media offer about the topic being addressed, and create opportunities for questioning, for reflection, and for taking a moral and social position in relation to it. In this way, they promote young people media literacy, using media potentialities as a resource.

Despite all the work possibilities referred previously, it should be borne in mind, however, that "teaching students to be critical of the media is not the same as teaching them to think critically" (Scheibe and Rogow, p.56). And this discernment is an essential component of the challenge that media literacy education constitutes in today's society.

Media education thus emerges as a privileged area of intervention, if the goal is to educate informed, thoughtful, and conscientious citizens about the ethical issues involved in their behavior as consumers, as communicators and producers (what Jenkins, 2006, refers to as an "Ethics challenge "). The challenges faced by media education are therefore great and, given the ubiquity of the new media, its success depends on multiple actors and on the work developed in multiple contexts. The actions of governments, supranational 
institutions, schools, non-formal education institutions, nongovernmental organizations, families, the media themselves and the community as a whole, all compete for the final aim of promoting young people's media literacy.

\section{References}

Aboujaoude E., Savage M.W., Starcevic V., Salame W.O., 2015. "Cyberbullying: Review of an old problem gone viral, Journal of Adolescent Health, 57, pp. 10-18.

Almeida A., Correia I., Marinho S., Garcia D'J., 2012. "Virtual but not less real: A study of cyberbullying and its relations to moral disengagement and empathy", In: Li Q., Cross D., Smith P.K. (Eds.), Cyberbullying in the global playground: Research from international perspectives, pp.223-244. Oxford: Wiley-Blackwell.

Amichai-Hamburger Y., 2007. "Personality, individual differences and internet use", In: Joinson A., McKenna K., Postmes T., Reips U.-D. (Eds.), The Oxford Handbook of Internet Psychology, pp. 204-221. New York: Oxford University Press.

Bawden D., 2008. "Origins and concepts of digital literacy", In: Lankshear, C. and Knobel, M. (Eds), Digital literacies: Concepts, policies and practices, pp. 17-32. New York: Peter Lang

Bazalgette C., 1989. Primary media education: A curriculum statement. Londres: British Film Institute.

Boyd D. 2008. "Why youth social network sites: The role of networked publics in teenage social life", MacArthur Foundation Series on Digital Media and Learning - Youth, identity and digital media (Buckingham D., ed.), pp.119-142. Cambridge, MA: The MIT Press.

Buckingham D., 2003. Media education: Literacy, learning and contemporary culture, Cambridge: Polity.

Buckingham D., 2008. "Defining digital literacy - What do young people need to know about digital media?", In: Lankshear C. and Knobel M. (Eds), Digital literacies: Concepts, policies and practices, pp.17-32. New York: Peter Lang.

Callister T.A., 2000. "Media literacy: On-Ramp to the literacy of the 21 st century or cul-de-sac on the information superhighway", In: Pailliotet A.W. and Mosenthal P. (Eds.), Reconceptualizing literacy in the media age, pp.403-429. Oxford: Elsevier Science.

Cassidy W., Faucher C., Jackson M., 2013. "Cyberbullying among youth: A comprehensive review of current international research and its implications and application to policy and practice", School Psychology International, 34(6), pp.575-612.

Duncan B. and Pungente J., 1989. Media literacy resource guide. Toronto: Ontario Ministry of Education.

Ferrés J. and Piscitelli A., 2012. "La competencia mediática: Popuesta articulada de dimensiones e indicadores". Comunicar, 38, XIX, pp. 75-82

Frau-Meigs D., 2006. Media education: A kit for teachers, students, parents and professionals. Paris: UNESCO

Gini G., Albiero P., Benelli B., Altoè G., 2007. "Does empathy predict adolescents' bullying and defending behavior?" Aggressive Behavior, 33, pp. 467-476.

Hobbs R., 2010. Digital and media literacy: A plan of action. Washington, DC: The Aspen Institute.

Jäger T., Stelter C., Amado J., Matos A., Pessoa T. (Eds.) 2012. Cyberbullying - Um manual de formação de pais. http://ct4p.zepf.eu/CT4P_Training_manual_PT.pdf ; retrived January 5, 2017.

Jacquinot-Delaunay G., Carlsson U., Tayie T., Pérez Tornero J.M., 2008. "Empowerment through media education. An intercultural approach", In: Carlsson, Tayie U., Jacquinot S., Pérez Tornero J.M. (Eds.), Empowerment through media education: An intercultural dialogue, pp.19-33. Göteborg: Nordicom, The International Clearinghouse on Children, Youth and Media.

Jenkins H., Clinton K., Purushotma R., Robison A., Weigel M., 2006. Confronting the challenges of participatory culture: Media education for the 21st century. Chicago: The MacArthur Foundation. 
Mascheroni G., Cuman A., 2014. Net children go mobile: Final report. Deliverables D6.4 and D5.2. Milano: Educatt. Http://Www.Netchildrengomobile.Eu/Reports/ ; retrieved December 27, 2016

Masterman L., 1985. Teaching the Media. London: Routledge.

Matos A. and Seixas A.M., 2016. "How schools can prevent, detect and handle cyber bullying", In: Samnoen O. (Ed.), Children, teenagers and cyber bullying: A guidebook for parents and schools, pp. 40-54. Ankara: Hakan SAKA (Tasarımedya Reklam), T.C. The Ministry of Culture and Tourism, General Directorate of Libraries and Publications.

McKenna K., 2007. "Through the internet looking glass. Expressing and validating the true self", In: Joinson A., McKenna K., Postmes T., Reips U.-D. (Eds.), The Oxford Handbook of Internet Psychology, pp.187-204. New York: Oxford University Press.

McKenna K., 2015. "Do outro lado do espelho da Internet. Exprimir e validar o 'verdadeiro eu'", In: Miranda G.L. (Org.), Psicologia dos comportamentos online (pp.195-226). Lisboa: Relógio d'Água Editores.

Ohler J.B., 2010. Digital Community digital Citizen. Thousand Oaks, California: Corwin.

Pérez Tornero J.M., 2008. "Media literacy. New conceptualisation, new approach", In: Carlsson U., Tayie S., Jacquinot G., Pérez Tornero J.M. (Eds.), Empowerment through media education: An intercultural dialogue, pp. 103-116. Göteborg: Nordicom, The International Clearinghouse on Children, Youth and Media

Pérez Tornero J.M. and Varis T., 2010. Media literacy and new humanism. Moscow: UNESCO. http://unesdoc.unesco.org/images/0019/001921/192134e.pdf.; retrieved December 12, 2016.

Potter W.J., 1998. Media literacy. California: Sage.

Prensky M., 2001. "Digital natives, digital immigrants, On the Horizon", NCB University Press, Vol. 9(5). Web resource.

Scheibe C. and Rogow F., 2012. The teacher's guide to media literacy: Critical thinking in a multimedia world. Thousand Oaks, California: Corwin.

Smith P.K., 2015. "The nature of cyberbullying and what we can do about it", Journal of Research in Special Educational Needs, 15(3), pp. 176-184.

Snakenborg J., Van Acker R., Gable R.A., 2011. "Cyberbullying: Prevention and intervention to protect our children and youth", Preventing School Failure: Alternative Education for Children and Youth, 55(2), pp.88-95.

Valkenburg P.M. and Peter J., 2009. "Social consequences of the internet for adolescents: A decade of research". Current Directions in Psychological Science, 18(1), pp.1-5.

Valkenburg P.M. and Peter J., 2011. "Online communication among adolescents: An integrated model of its attraction, opportunities, and risks", Journal Of Adolescent Health, 48, pp.121-127.

Willard N. 2004. I can't see you - You can't see me - How the use of information and communication technologies can impact responsible behavior. Web resource. 